\title{
PD-1 blockade delays tumor growth by inhibiting an intrinsic SHP2/Ras/MAPK signalling in thyroid cancer cells
}

Federica Liotti ${ }^{1}$, Narender Kumar ${ }^{1}$, Nella Prevete ${ }^{1,2}$, Maria Marotta ${ }^{3}$, Daniela Sorriento ${ }^{4}$, Caterina leranò ${ }^{5}$, Andrea Ronchi ${ }^{6}$, Federica Zito Marino ${ }^{6}$, Sonia Moretti ${ }^{7}$, Renato Colella ${ }^{8}$, Efiso Puxeddu ${ }^{7}$, Simona Paladino ${ }^{3}$, Yoshihito Kano ${ }^{9}$, Michael Ohh ${ }^{10,11}$, Stefania Scala ${ }^{5}$ and Rosa Marina Melillo $0^{1,3^{*}}$

\begin{abstract}
Background: The programmed cell death-1 (PD-1) receptor and its ligands PD-L1 and PD-L2 are immune checkpoints that suppress anti-cancer immunity. Typically, cancer cells express the PD-Ls that bind PD-1 on immune cells, inhibiting their activity. Recently, PD-1 expression has also been found in cancer cells. Here, we analysed expression and functions of PD-1 in thyroid cancer (TC).
\end{abstract}

Methods: PD-1 expression was evaluated by immunohistochemistry on human TC samples and by RT-PCR, western blot and FACS on TC cell lines. Proliferation and migration of TC cells in culture were assessed by BrdU incorporation and Boyden chamber assays. Biochemical studies were performed by western blot, immunoprecipitation, pull-down and phosphatase assays. TC cell tumorigenicity was assessed by xenotransplants in nude mice.

Results: Human TC specimens (47\%), but not normal thyroids, displayed PD-1 expression in epithelial cells, which significantly correlated with tumour stage and lymph-node metastasis. PD-1 was also constitutively expressed on TC cell lines. PD-1 overexpression/stimulation promoted TC cell proliferation and migration. Accordingly, PD-1 genetic/ pharmacologic inhibition caused the opposite effects. Mechanistically, PD-1 recruited the SHP2 phosphatase to the plasma membrane and potentiated its phosphatase activity. SHP2 enhanced Ras activation by dephosphorylating its inhibitory tyrosine 32, thus triggering the MAPK cascade. SHP2, BRAF and MEK were necessary for PD-1-mediated biologic functions. PD-1 inhibition decreased, while PD-1 enforced expression facilitated, TC cell xenograft growth in mice by affecting tumour cell proliferation.

Conclusions: PD-1 circuit blockade in TC, besides restoring anti-cancer immunity, could also directly impair TC cell growth by inhibiting the SHP2/Ras/MAPK signalling pathway.

Keywords: Thyroid Cancer, Programmed cell death-1, SHP2 phosphatase, Ras, MAPK signalling

* Correspondence: rosmelil@unina.it

${ }^{1}$ Institute of Experimental Endocrinology and Oncology (IEOS), CNR, Naples, Italy

${ }^{3}$ Department of Molecular Medicine and Medical Biotechnology, University of Naples Federico II, Via S. Pansini 5, 80131 Naples, Italy

Full list of author information is available at the end of the article

\section{Background}

Immunotherapy represents the major breakthrough of the last years in the therapy of several cancer types [1]. The programmed cell death-ligand 1 and 2 (PD-L1, PDL2) are immune checkpoints (IC) important for delivering inhibitory signals to immune cells expressing their receptor programmed cell death-1 (PD-1) [1, 2]. This

C C The Author(s). 2021 Open Access This article is licensed under a Creative Commons Attribution 4.0 International License, which permits use, sharing, adaptation, distribution and reproduction in any medium or format, as long as you give appropriate credit to the original author(s) and the source, provide a link to the Creative Commons licence, and indicate if changes were made. The images or other third party material in this article are included in the article's Creative Commons licence, unless indicated otherwise in a credit line to the material. If material is not included in the article's Creative Commons licence and your intended use is not permitted by statutory regulation or exceeds the permitted use, you will need to obtain permission directly from the copyright holder. To view a copy of this licence, visit http://creativecommons.org/licenses/by/4.0/ The Creative Commons Public Domain Dedication waiver (http://creativecommons.org/publicdomain/zero/1.0/) applies to the data made available in this article, unless otherwise stated in a credit line to the data. 
circuit is critical in regulating immune tolerance in various physiologic and pathologic contexts [1]. Cancer cells suppress anti-cancer immune response exploiting the PD-1 circuit [3]. Typically, PD-Ls are expressed by cancer cells, while PD-1 is expressed by immune cells with anti-cancer potential (i.e., $\mathrm{T}$ cells, macrophages or natural killer cells) [3]. The inhibition of this circuit through immune checkpoint inhibitors (ICI) - neutralizing antibodies against PD-1, PD-L1 or PD-L2 - restores the anti-cancer immune response and displays therapeutic activity in various cancer types [4].

Recently, various tumour types have been found to express also intrinsic PD-1 (i.e., melanoma, hepatocarcinoma, lung carcinoma and T-cell lymphomas) [5-8]. PD-1 intrinsic signalling promoted tumour growth in melanoma and hepatocarcinoma through a mammalian target of rapamycin (mTOR)/ribosomal protein S6 Kinase (S6K1) pathway $[5,6]$. By contrast, in non-small cell lung cancer (NSCLC) and in T-cell lymphomas, PD-1 behaved as a tumour suppressor $[7,8]$. These data indicate that PD-1 could exert context-related tumourintrinsic functions other than the suppression of immune response, and suggest the need of wider studies on ICI effects on the entire tumour context.

Thyroid carcinoma (TC) is the most frequent endocrine malignancy. Follicular cell-derived TC includes different histotypes ranging from well differentiated (WDTC) to poorly differentiated (PDTC) and undifferentiated/anaplastic (ATC) carcinomas. WDTCs include papillary histotype (PTC), representing the majority of these tumours, and follicular histotype (FTC). WDTCs show an indolent behaviour and are mainly cured by surgery and ${ }^{131}$ I radioiodine (RAI) therapy; only a small percentage of them exhibits recurrence, metastasis and resistance to RAI over time. By contrast, aggressive forms of TC (PDTC and ATC) represent a clinic challenge displaying a remarkable chemo- and radioresistant phenotype from the beginning $[9,10]$. Interestingly, aggressive forms of TC exhibit increased immune checkpoint expression and inefficient immune infiltrate $[9,11-14]$, features that are being evaluated for the treatment of the disease $[9,14,15]$.

Here, we analysed the PD-1/PD-Ls circuit in TC showing that: i) TC cell lines and TC human samples express, besides PD-Ls, as already demonstrated [16-18], also PD-1 in epithelial cells, whose levels correlated with tumour aggressiveness; ii) intrinsic PD-1 sustains proliferation and migration of TC cells through a SHP2/Ras/ MAPK signalling cascade; iii) PD-1 overexpression promotes, while PD-1 blockade inhibits, ATC xenograft growth by affecting cancer cell proliferation.

Thus, TCs express an intrinsic pro-tumorigenic PD-1 circuit. In TC context, the oncogenic role of PD-1 is dependent on the activation of the Ras/MAPK cascade.
PD-1 blockade may represent a rational therapeutic choice in aggressive forms of $\mathrm{TC}$ for both immune response reconstitution and direct anti-tumour effects.

\section{Materials and methods Reagents}

pCMV3 and pCMV3 PD-1 plasmids were from Sinobiological (Wayne, PA, USA), pCEFL and pCEFL AU5tagged Ras (V12) plasmids were a kind gift of J.S. Gutkind [19]. PD-1 was cloned in pFLAG 5A (Invitrogen, Carlsbad, CA, USA). Soluble PD-L1 (sPD-L1) was from R\&D systems (Minneapolis, MN, USA), Nivolumab was kindly provided by S. Scala. Anti-Ras antibody for immunoprecipitation (clone MA1012) was from Invitrogen. Anti-phospho Y32, anti-phospho Y64 Ras antibodies and Y32 and Y64 peptides, used to saturate aspecific binding of each antibody, were provided by M. Ohh. SHP099, Vemurafenib, and Selumetinib were from Selleckchem

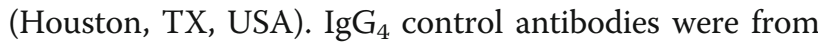
Invitrogen.

\section{Cell culture and transfection}

Human thyroid cancer cell lines BcPAP, TPC-1, 8505c, CAL62, SW1736, FRO, BHT101, HTH7 and OCUT1 were obtained and maintained as previously described [20]. The normal thyroid cells H-6040, isolated from normal human thyroid tissue and cultured in Human Epithelial Cell Medium with the addition of InsulinTransferrin-Selenium, EGF, Hydrocortisone, LGlutamine, antibiotic-antimycotic solution, Epithelial Cell supplement, and FBS were purchased from Cell Biologics (Chicago, IL, USA). H-6040 cells were used at passages between 3 and 6 .

Transient transfections of TC cells were performed using polyethylenimine according to manufacturer's instructions (Merck, Darmstadt, Germany). Cells were harvested $48 \mathrm{~h}$ after transfection. Electroporation was used (Neon ${ }^{\circ}$ Transfection System for Electroporation, Life Technologies, Carlsbad, CA, USA) to obtain stably transfected cells [21].

For RNA interference, we used SMART pools of siRNA from Dharmacon (Lafayette, CO, USA) targeting PD-1 or SHP2. Transfection was carried out by using $100 \mathrm{nM}$ of SMARTpool and $6 \mu \mathrm{l}$ of DharmaFECT (Dharmacon) for $48 \mathrm{~h}$ [22].

\section{Cytofluorimetric analysis}

Cells were incubated $\left(30 \mathrm{~min}\right.$ at $\left.4{ }^{\circ} \mathrm{C}\right)$ with specific or isotype control antibodies. Cells were analysed with a FACS Calibur cytofluorimeter using CellQuest software (BD Biosciences, Mississauga, ON, Canada). $10^{4}$ events for each sample were acquired [22]. Anti-PD-1 and antiPD-L1 antibodies were from ebioscience (Thermo 
Fisher, Waltham, MA, USA), anti-PD-L2 from Miltenyi Biotec (Bergisch Gladbach, Germany).

\section{Immunohistochemistry}

Thyroid carcinomas were selected from the Pathology Unit of the University of Perugia upon informed consent; the protocol for the study was approved by the institutional committee of University of Perugia. Thyroid tissues were formalin fixed and paraffin embedded (FFPE). Sections of $4 \mu \mathrm{m}$ were obtained. BOND-III fully automated immunohistochemistry stainer (Leica Biosystems, Wetzlar, Germany) carried out the immunostaining, using heat-induced antigen retrieval at $\mathrm{pH} 9.0$ for $20 \mathrm{~min}$, followed by primary antibody (PD-1, clone EH33; dilution 1:200) (Cell Signaling, Beverly, MA, USA) incubation for $15 \mathrm{~min}$. Finally, the ready to use Bond ${ }^{\mathrm{mix}}$ Polymer Refine Detection System allowed the detection of antigen-antibody reaction [11]. Immunohistochemical (IHC) score was calculated by combining the staining intensity with the percentage of immuno-reactive epithelial cells. Staining intensity was rated on a scale of $0-3(0$, negative; 1 , weak; 2, moderate; and 3 , strong). Each tumor was then scored for the percentage of immunoreactive cells. The IHC score was then assigned to each tumor by multiplying the percentage of positive epithelial cells for the staining intensity. The IHC score ranged from 0 to 300 . We used a cut-off of $5 \%$ to determine the positivity of immunohistochemistry, consistently with the cut-off chosen to evaluate PD-1 in other cancer systems $[6,23,24]$.

\section{S-phase entry}

S-phase entry was evaluated by Bromodeoxyuridine (BrdU) incorporation. Cells were serum-deprived and treated with stimuli for $24 \mathrm{~h}$. BrdU was added at a concentration of $10 \mu \mathrm{M}$ for the last $1 \mathrm{~h}$. BrdU-positive cells were revealed with Texas Red conjugated secondary Abs (Jackson Laboratories, West Grove, PA, USA). Fluorescence was detected by FACS analysis [25].

\section{Migration assays}

Chemotaxis was evaluated using a Boyden chamber. We used a 48-well microchemotaxis chamber (NeuroProbe, Gaithersburg, MD, USA) and 8- $\mu \mathrm{m}$-pore polycarbonate membranes (Nucleopore, Pleasanton, CA, USA) coated with $10 \mu \mathrm{g} / \mathrm{ml}$ fibronectin (Merck) as described elsewhere [22].

\section{Protein studies}

Protein extraction and immunoblotting experiments were performed according to standard procedures [26]. Antibodies to PD-1, phospho-PD-1, phospho-BRAF, phospho-MEK1/2, phospho-MAPK (p44/p42), Ras, phospho-SHP2, SHP2, and GRB2 for Western blot analysis were obtained from Cell Signaling Technology (Danvers, MA, USA). Monoclonal anti-tubulin antibody was from Sigma Aldrich. Secondary anti-mouse and anti-rabbit antibodies were coupled to horseradish peroxidase (Biorad, Hercules, CA, USA).

Cell lysates were subjected to immunoprecipitation with different antibodies or subjected to pull-down binding assays with purified recombinant proteins immobilized on agarose beads. The glutathione-S-transferases (GST) fusion proteins were expressed in Escherichia coli and purified with glutathione-conjugated agarose beads (Merck) by standard procedures. The protein complexes were eluted and resolved by sodium dodecyl sulphatepolyacrylamide gel electrophoresis (SDS-PAGE). Immunoblotting with specific antibodies and enhanced chemiluminescence (ECL; Thermo Fisher) were employed for immune-detection of proteins in complexes [27].

Cell fractionation experiments were performed using the Subcellular Protein Fractionation Kit for Cultured Cells according to manufacturer's instructions (Thermo Fisher). Membrane fraction's protein content was normalized by using anti-transferrin receptor antibody (Invitrogen).

\section{Immunofluorescence}

Cells, grown on coverslips, were washed with phosphatebuffered saline (PBS), fixed with $4 \%$ paraformaldehyde (PFA) and quenched with $50 \mathrm{mM} \mathrm{NH}_{4} \mathrm{Cl}$. Then, cells were permeabilized with $0.2 \%$ Triton X-100 for $5 \mathrm{~min}$ and blocked for $30 \mathrm{~min}$ in PBS containing 5\% FBS and $0.5 \%$ bovine serum albumin (BSA). Primary antibodies were detected with Alexa Fluor546-conjugated secondary antibodies (Abcam, Cambrige, UK). Images were acquired using a laser scanning confocal microscope (LSM 510; Carl Zeiss MicroImaging, Inc., Oberkochen, Germania.) equipped with a planapo 63X oil-immersion (NA 1.4) objective lens by using the appropriate laser lines and setting the confocal pinhole to one Airy unit. Zslices from the top to the bottom of the cell by using the same setting (laser power, detector gain) were collected as previously described [28].

\section{SHP2 activity assay}

SHP2 phosphatase activity was determined using the human/mouse/rat active DuoSet IC kit (R\&D Systems). Briefly, cellular SHP2 bound to anti-SHP2 antibody conjugated to agarose beads was exposed to synthetic phosphopeptide substrate, which is only dephosphorylated by active SHP2. The amount of free phosphate generated in the supernatant was determined, as absorbance at 620 $\mathrm{nm}$, by a sensitive dye-binding assay using malachite green and molybdic acid and represents a direct measurement of SHP2 activity in the cellular system [29]. 


\section{Tumorigenicity in immunocompromised mice}

Each group of 8 mice (6-week-old CD1 nu/nu females) was inoculated subcutaneously with $8505 \mathrm{c}$ parental cells, $8505 \mathrm{c}$ transfected with pCMV3 or pCMV3 PD-1 cells ( $1 \times 10^{7}$ cells/mouse, two clones) [25]. Nivolumab (antiPD-1) or control $\operatorname{IgG}_{4}$ were intraperitoneally (i.p.) administered at $30 \mathrm{mg} / \mathrm{kg}$ twice per week. The experimental protocol for animal studies was approved by the Ministero Italiano della Salute (No. 317/2019-PR). For xenograft histological analysis, anti-Ki-67 was from Biocare Medical (Pacheco, CA, USA), anti-CD31, anticleaved caspase 3 were from R\&D Systems.

\section{Statistical analysis}

The results are expressed as the mean \pm SD of at least 3 experiments. Values from groups were compared using the paired Student $t$ test or Duncan test. The association between PD-1 expression and clinic-pathologic parameters in immunohistochemistry experiments was conducted using $x^{2} . P$ value $<0.05$ was considered statistically significant.

\section{Results}

PD-1 receptor and its ligands are expressed in thyroid carcinoma cells

We evaluated the expression levels of PD-1, PD-L1 and PD-L2 in a panel of human TC cell lines derived from PTC (BcPAP, TPC-1) or ATC (8505c, CAL62, SW1736, FRO, BHT101, HTH7, OCUT1) compared to a primary human thyroid cell culture (H-6040). Cytofluorimetric analysis demonstrated that all the cell lines expressed PD-1 on the plasma membrane, though to a lesser extent than PD-Ls, and that PD-1 protein levels were higher in cancer compared to normal thyroid cells (Fig. 1a). Similar data were also obtained through western blot analysis as shown in Supplementary Figure 1A. PD-1, PD-L1 and PD-L2 mRNA levels were comparable between normal and cancerous thyroid cells, suggesting that post-translational mechanisms could be responsible for the protein increase observed in cancer cells (Suppl. Fig. 1b).

Immunohistochemical (IHC) staining of whole sections from 34 PTC surgical samples with anti-PD-1 antibodies showed that PD-1 is expressed in TC cells (Fig. 1b), but not in normal thyroid epithelial cells (not shown). Figure $1 \mathrm{~b}$ shows a representative PTC case with PD-1 immunoreactivity, cytosolic and/or localized at the plasma membrane, in thyroid cancer epithelial cells $(20 \mathrm{x}$ and 40x) (Fig. 1b). Infiltrating lymphocytes showed a stronger PD-1 staining compared to cancer cells. PD-1 expression was detectable in epithelial cancerous cells of $47 \%$ of tumour samples (Table 1). By analysing clinicpathologic features of the PTC samples, we found that tumour stage and lymph-nodal metastasis significantly correlated with PD-1 staining (Table 1) in our casistic.

Several reports already described the expression of PD-L1 in TC cells of human samples and demonstrated that its expression is associated with aggressiveness, suggesting that PD-L1 could represent a useful prognostic marker for TC patients [16-18]. We also confirmed in our casistic the expression of the PD-L1 in thyroid cancer epithelial cells (Fig. 1b).

Altogether, our data on TC samples, on TC cell lines and the data available from the literature indicate that TC cells can express PD- 1 together with its ligands. Our results also indicate that PD-1 expression correlates with tumour malignancy.

\section{PD-1 promotes thyroid carcinoma cell proliferation and motility}

We selected $8505 \mathrm{c}$ and TPC-1 cells - derived from a human ATC and PTC, respectively - to analyse the biologic effects of PD-1 enforced expression or of PD-1 stimulation by soluble PD-L1 (sPD-L1-1 $\mu \mathrm{g} / \mathrm{ml}$ ). Levels of PD-1 expression upon transient transfection are shown in Suppl. Fig. 2a. The endogenous PD-1 protein expression levels, already shown in TC wild-type cells (Suppl. Fig. 1A), are not evident in the empty-vector transfected cells due to the short time of exposure (Suppl. Fig. 2A).

We demonstrated that transient PD-1 overexpression (pFLAG PD-1 compared to pFLAG) or PD-1 activation (sPD-L1 vs untreated - NT) significantly increased DNA synthesis, as assessed by BrdU incorporation (Fig. 2a) in both TC cell lines. Accordingly, cell cycle analysis showed an increased percentage of cells in S and G2/M phases in PD-1-transfected compared to empty vectortransfected TC cells (Suppl. Fig. 2B). No effects of PD-1 overexpression/activation were observed on cell viability (Suppl. Fig. 2C).

In order to confirm these observations, we evaluated the effects of PD-1 inhibition on the same cellular functions. To this aim, PD-1 expression was inhibited by siRNA or Nivolumab (anti-PD-1 moAb) in TPC-1 and 8505c cells. Both siRNAs targeting PD-1 (siPD-1 vs siCTR - 100 nM; Suppl. Fig. 2D) and Nivolumab (Nivo $10 \mu \mathrm{g} / \mathrm{ml}$ ) were able to significantly inhibit BrdU incorporation (Fig. 2b) and cell cycle progression (Suppl. Fig. $2 \mathrm{E}$ ) of TC cells in comparison to the relative controls, without affecting cell viability (Suppl. Fig. 2F).

To assess the role of endogenous PD-1 ligands in TC cell proliferation, we treated $8505 \mathrm{c}$ cells with blocking anti-PD-L1 or anti-PD-L2 moAb $(10 \mu \mathrm{g} / \mathrm{ml})$ or transiently transfected them with PD-L1 or PD-L2 expressing vectors. PD-L1 or PD-L2 overexpression increased, while anti-PD-L1 or anti-PD-L2 antibodies inhibited, BrdU incorporation in 8505c cells (Suppl. Fig. 2G). No effects of 

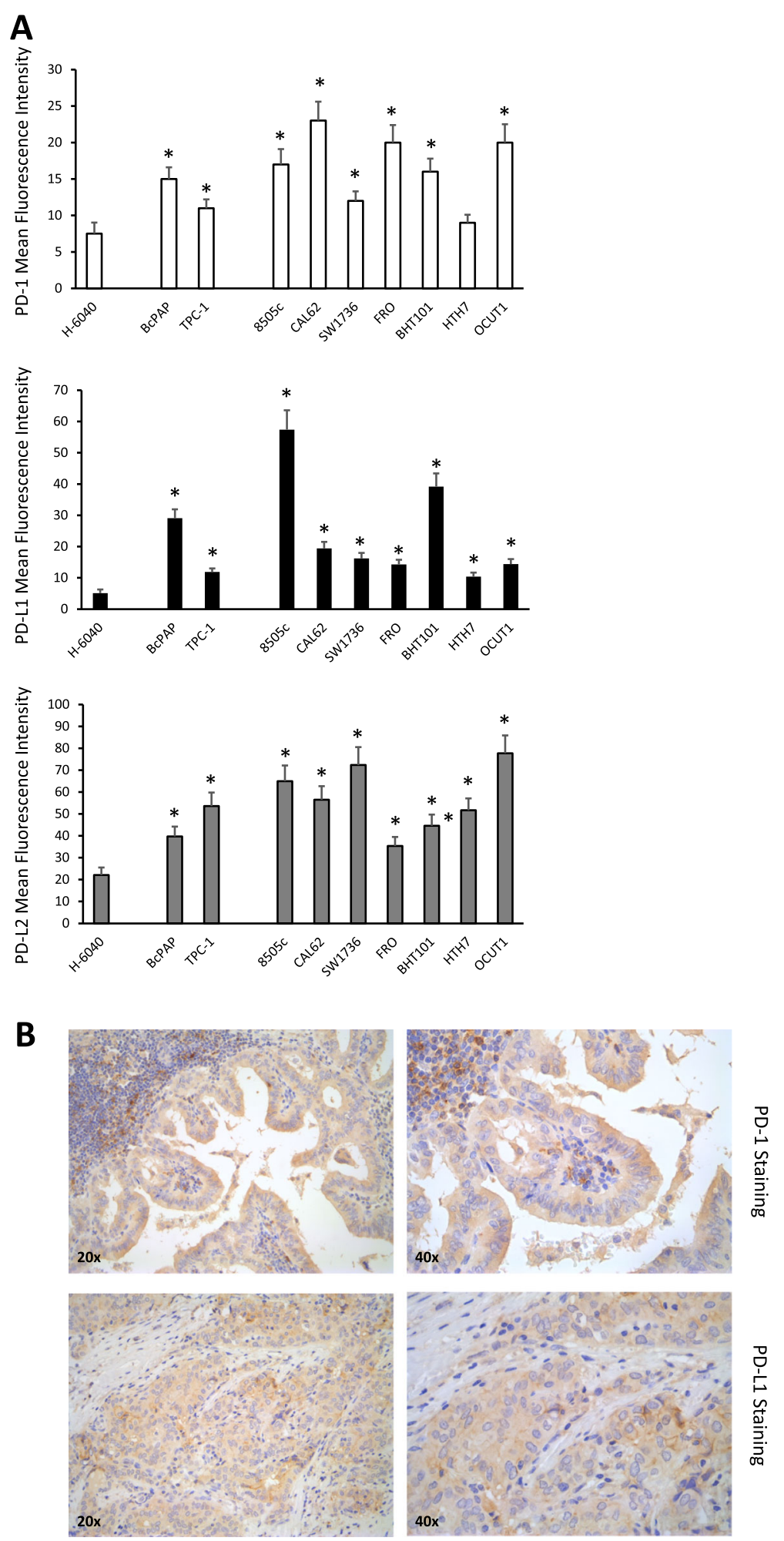

Fig. 1 Immune checkpoint expression in thyroid cancer (TC) cells and human TC tissue samples. a. Mean Fluorescence Intensity for PD-1, PD-L1 and PD-L2 measured by flow cytometric analysis on H-6040 normal thyroid epithelial cells, PTC-derived cell lines (BCPAP and TPC-1), and ATCderived cell lines (8505C, CAL62, SW1736, FRO, BHT101, HTH7, OCUT1). Data are presented as mean \pm SD. * $P<0.05$ compared to the H-6040 cells. b. Immunohistochemical staining of representative PTC samples with anti-PD-1 or anti-PD-L1 antibodies (20x and 40x). In the upper panels, PD-1 immunoreactivity in both thyroid epithelial cells and in infiltrating lymphocytes can be detected. Lower panels show PD-L1 immunoreactivity in a representative PTC sample 
Table 1 Relation between PD-1 epithelial TC cell expression and clinic-pathological features. ${ }^{*} P<0.05$ among groups

\begin{tabular}{|c|c|c|c|}
\hline & \multicolumn{2}{|c|}{ Epithelial cell PD-1 staining } & \multirow[t]{2}{*}{$P$} \\
\hline & Negative/low & Positive & \\
\hline \multicolumn{4}{|l|}{$\operatorname{BRAF}(n=34)$} \\
\hline Not mutated & 2 & 2 & 0.9 \\
\hline Mutated & 16 & 14 & \\
\hline \multicolumn{4}{|c|}{ Thyroiditis ( $n=33$ ) } \\
\hline No & 12 & 11 & 0.9 \\
\hline Yes & 5 & 5 & \\
\hline \multicolumn{4}{|l|}{ TNM $(n=34)$} \\
\hline T1 & 11 & 9 & \\
\hline $\mathrm{T} 2$ & 4 & 3 & 0.77 \\
\hline T3 & 3 & 4 & \\
\hline NO & 17 & 6 & \\
\hline N1 & 1 & 10 & $0.04^{*}$ \\
\hline MO & 11 & 15 & \\
\hline M1 & 7 & 1 & 0.9 \\
\hline \multicolumn{4}{|c|}{ Progression free survival $(n=28)$} \\
\hline No & 3 & 4 & \\
\hline Yes & 12 & 9 & 0.51 \\
\hline \multicolumn{4}{|l|}{ Stage $(n=29)$} \\
\hline 1 & 12 & 6 & \\
\hline 2 & 0 & 0 & $0.04^{*}$ \\
\hline 3 & 1 & 5 & \\
\hline 4 & 2 & 3 & \\
\hline \multicolumn{4}{|c|}{ Infiltrative phenotype $(n=34)$} \\
\hline No & 15 & 13 & \\
\hline Yes & 3 & 3 & 0.87 \\
\hline
\end{tabular}

PD-L1 or PD-L2 were observed on TC cell viability (not shown).

Since PD-1 expression levels in human TC samples correlated with lymph-nodal metastasis, we asked whether PD-1 could also stimulate the motility of TC cells. To this aim, we performed migration assays on $8505 \mathrm{c}$ cells stably overexpressing or not PD-1 [pCMV3 PD-1 cl13 and cl16 compared to pCMV3 empty vector-transfected cells (Suppl. Fig. 3A)] or on parental $8505 \mathrm{c}$ cells treated or not with sPD-L1 $(1 \mu \mathrm{g} /$ $\mathrm{ml}$ ) in the presence or absence of Nivolumab (Nivo $10 \mu \mathrm{g} / \mathrm{ml}$ ) (Fig. 2c). PD-1 overexpressing TC cells showed an increased constitutive migratory potential compared to control cells. Consistently, sPD-L1 induced, and Nivolumab inhibited, both basal and sPDL1-induced migration (Fig. 2c).

These data indicate that PD-1 intrinsic circuit sustains $\mathrm{TC}$ cell proliferation and migration.
PD-1 activates the Ras/MAPK signalling cascade in thyroid carcinoma cells

We then asked which signalling pathway was stimulated upon PD-1 overexpression/activation. To this aim, we used specific phospho-antibodies against various signalling proteins. We found that BRAF, MEK and MAPK (p44/p42) are activated, as demonstrated by the increased levels of their phosphorylated forms, upon PD-1 transient transfection (Fig. 3a), PD-1 stable transfection (Suppl. Fig. 3B), and sPD-L1 treatment (Fig. 3b) in both $8505 \mathrm{c}$ and TPC-1 cells. No significant activation of other signalling proteins was detected (Suppl. Fig. 3C). To confirm these observations, BRAF, MEK1/2 and MAPK activation levels were evaluated upon PD-1 blockade by siPD-1 or Nivolumab treatment. Consistently, both siPD-1 $(100 \mathrm{nM})$ and Nivolumab $(10 \mu \mathrm{g} / \mathrm{ml}-15$ and 30 min) reduced the levels of phosphorylated BRAF, MEK1/2 and MAPK compared to the relative controls (Fig. 3c) in TC cells.

Since the BRAF/MEK/MAPK signalling is potentiated by PD-1 in TC cells, and Ras GTPase is the main upstream activator of this cascade [30], we asked whether PD-1 could activate Ras. To this end, we used a pulldown assay with the GST-RAF1-Ras binding domain (RBD), which specifically binds the GTP-loaded active form of Ras. 8505c and TPC-1 cells were transiently transfected with empty vector (pFLAG) or PD-1 (pFLAG PD-1) in combination with PCEFL H-Ras AU5 or the relative empty vector ( $\mathrm{pCEFL).} \mathrm{PD-1} \mathrm{enforced} \mathrm{expression}$ increased Ras activation, as assessed by Ras pull-down, in comparison to control (Fig. 3d), suggesting that PD-1 potentiates Ras activation in TC cells.

\section{PD-1 recruits and activates the SHP2 phosphatase in thyroid carcinoma cells}

In immune cells, PD-1 signalling requires the tyrosine phosphatase SHP2 (PTPN11) [29]. Upon phosphorylation of tyrosine residues in its cytosolic domain, PD-1 binds to the SH2 domains of SHP2 that, in turn, dephosphorylates signalling components of the immune receptors, thus down-regulating the immune responses [31]. In cancer cells, SHP2 acts as a signalling molecule downstream receptor tyrosine kinases (RTKs), displaying oncogenic activity [32]. In particular, SHP2 can contribute to Ras activation either by recruiting the GRB2/SOS complex to the plasma membrane [33] or through its phosphatase activity on Ras inhibitory tyrosine residues [33, 34].

We first asked whether PD-1 could physically interact with SHP2 in TC cells. Reciprocal co-immunoprecipitation experiments showed that endogenous and exogenously expressed PD-1 bind SHP2 in 8505c and TPC-1 cells (Fig. 4a). Moreover, pull-down assays with $\mathrm{N}$ - or Cterminal $\mathrm{SH} 2$ domain of SHP2 demonstrated that SHP2 

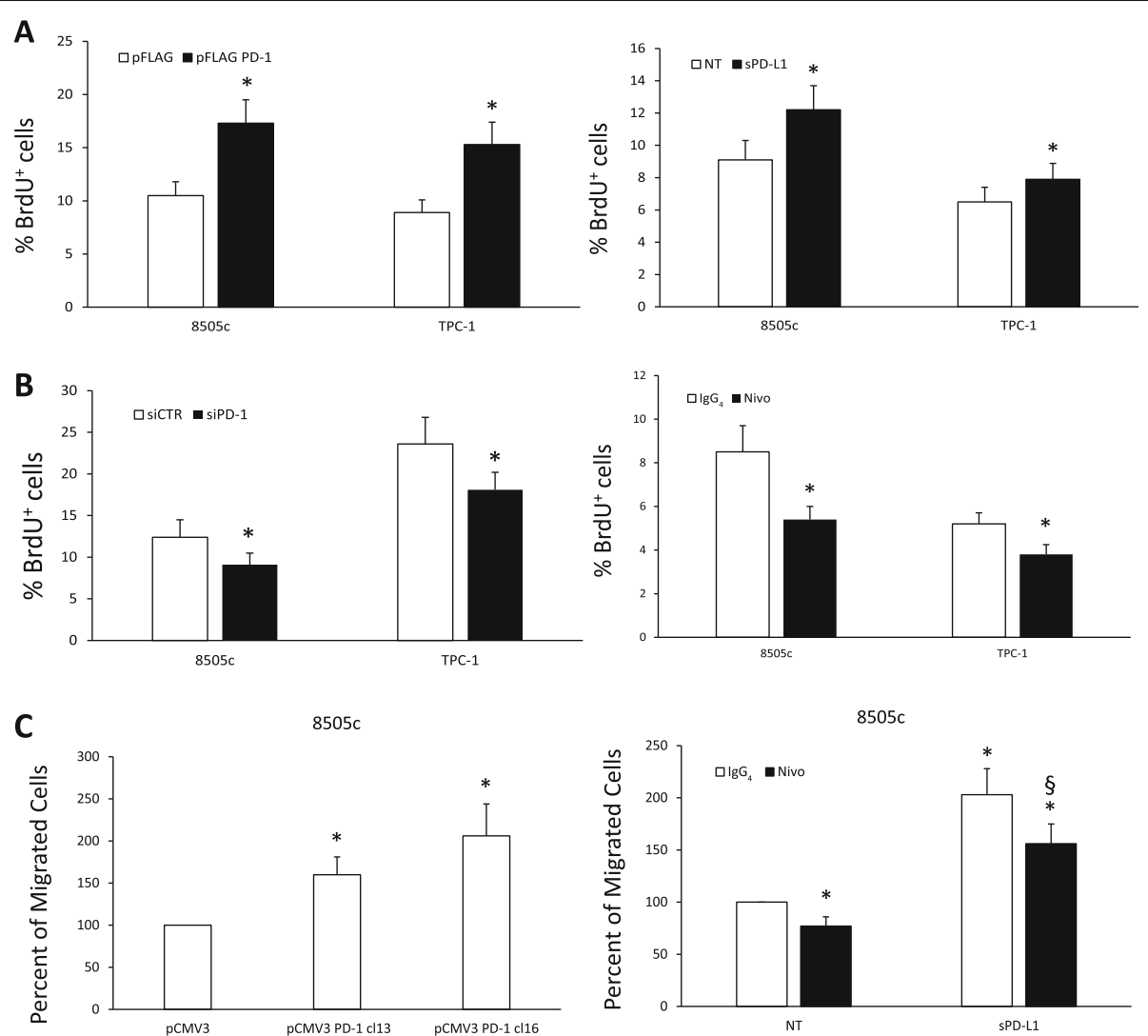

Fig. 2 Functional activity of intrinsic PD-1 in TC cells. a. DNA synthesis of 8505c and TPC-1 cells transiently transfected with pFLAG PD-1 or the relative empty vector (pFLAG), or treated or not with soluble PD-L1 (sPD-L1-1 $\mu \mathrm{g} / \mathrm{ml}$ ) assessed by BrdU incorporation. Data are presented as mean \pm SD of 5 independent experiments. $\mathbf{b}$. DNA synthesis of $8505 \mathrm{c}$ and TPC-1 cells treated with siRNA targeting PD-1 (siPD-1 - $100 \mathrm{nM}$ ) or the relative control (siCTR - $100 \mathrm{nM}$ ) for $48 \mathrm{~h}$ or treated with Nivolumab (Nivo $-10 \mu \mathrm{g} / \mathrm{ml}$ ) or control lgG $(10 \mu \mathrm{g} / \mathrm{ml})$ for $24 \mathrm{~h}$ assessed by BrdU incorporation. Data are presented as mean \pm SD of 5 independent experiments. c. Percent of migrated cells over control (empty vector transfected - pCMV3) of stably transfected 8505 c PD-1 cells versus $10 \%$ FBS, or of 8505 c cells treated with Nivolumab (Nivo - $10 \mu \mathrm{gg} / \mathrm{ml}$ ) or control $\operatorname{lgG}_{4}(10 \mu \mathrm{g} / \mathrm{ml})$ toward sPD-L1 $(1 \mu \mathrm{g} / \mathrm{ml})$ or medium alone (NT). Data are presented as mean \pm SD of 5 independent experiments. ${ }^{*} P<0.05$ compared to the relative untreated cells. $\S P<0.05$ compared to SPD-L1 alone

can bind PD-1 mainly through SHP2 C-terminal SH2 domain (Fig. 4b). In support of these observations, we found that both endogenous and exogenous PD-1 are tyrosine phosphorylated in TC cells (Suppl. Fig. 4A), condition necessary to allow the $\mathrm{SH} 2$ domains of SHP2 to bind PD-1 [33].

Cell fractionation of $8505 \mathrm{c}$ cells transiently or stably transfected with PD-1 was used to demonstrate that PD-1 binding to SHP2 enforced the membrane localization of SHP2. Subcellular fractions of membranes (M) or cytosol (C) were obtained from PD-1 overexpressing and from control cells (pFLAG-PD-1 vs pFLAG or pCMV3 PD-1 cl 16 vs pCMV3). Enrichment of SHP2 levels in the membrane fractions was observed in PD-1 overexpressing cells compared to empty-vector transfected cells. Normalizations of each extract were obtained by using antibodies to transferrin receptor for membrane fraction and antitubulin for cytosolic extract (Fig. 4c). In agreement with these observations, immunofluorescence (IF) assay of PD-
1 overexpressing TC cells showed a significant increase of SHP2 staining at the plasma membrane in cells overexpressing PD-1 compared to controls (Fig. 4d and Suppl. Fig. 4B). Although SHP2 displays a strong intracellular signal, an increase of the fluorescent signal at cell boundary and/or in surface structures (e.g., membrane protrusions, membrane ruffles) was observed in PD-1 overexpressing cells as indicated by the arrows (Fig. 4d and Suppl. Fig. $4 B)$. Furthermore, in $8505 \mathrm{c}$ cells transfected with PD-1GFP, we demonstrated by IF that SHP2 and PD-1-GFP co-localize at the plasma membrane (Suppl. Fig. 4C).

\section{SHP2 dephosphorylates and activates Ras in TC cells}

We then searched for the molecular mechanism of Ras activation mediated by the PD-1/SHP2 complex. We first asked whether PD-1 could enhance GRB2 recruitment by SHP2. To this aim, we used pull-down assays with GST-SH2-GRB2 fusion proteins and coimmunoprecipitation assays and we showed no 


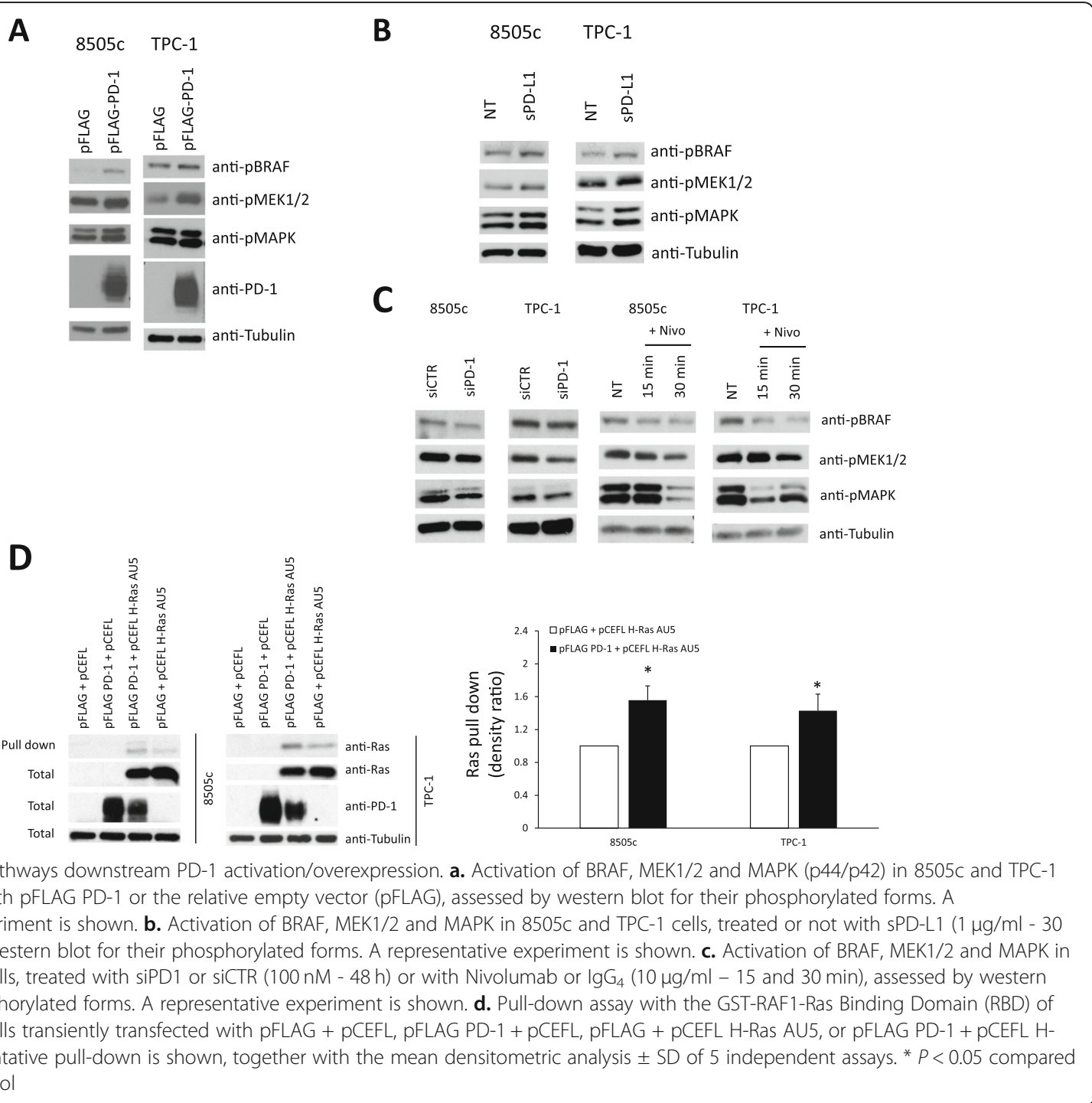

increased GRB2 binding to SHP2 in PD-1 transfected TC cells compared to controls (Suppl. Fig. 4D). In accordance with these observations, PD-1 enforced expression did not significantly increase SHP2 tyrosine phosphorylation levels (Suppl. Fig. 4A), on which GRB2 binding to SHP2 is dependent, nor changed substantially GRB2 compartmentalization as demonstrated in cell fractionation experiments (Fig. 4c).

Since the GRB2/SOS complex is not involved in PD-1-mediated Ras activation, we asked whether SHP2 could activate Ras through the dephosphorylation of its inhibitory tyrosine residues $[29,35]$. We evaluated the phosphatase activity of SHP2 and, in parallel, the levels of Ras tyrosine phosphorylation in cells overexpressing or not PD-1. We used a specific SHP2 phosphorylated substrate in the presence of the Malachite Green tracer, a colorimetric method for the detection of free inorganic phosphate [29]. We observed that SHP2 phosphatase activity was significantly increased in PD-1- versus empty-vectortransfected TC cells (Fig. 4e). Similar results were obtained in PD-1 stably transfected cells (not shown). Consistently with the increased phosphatase activity of SHP2, Ras total tyrosine phosphorylation levels, in the presence of PD-1, were significantly reduced in TC cells transfected with pCEFL H-Ras AU5 (Suppl. Fig. 4E). To assess whether Ras dephosphorylation occurs in its inhibitory residues 32 and/or 64 [29], we used (pan) Ras immunoprecipitation followed by immunoblotting with anti-phospho Y32 (Ras) or Y64 (Ras) antibodies. These experiments demonstrated that PD-1 enforced expression in 8505c cells reduced the Ras phosphorylation levels in the inhibitory tyrosine residues 32 in pCEFL Ras AU5-transfected cells compared to controls (Fig. 4f). Similar results were obtained in TPC-1 cells (not shown). No differences 
A

$8505 c$

TPC-1
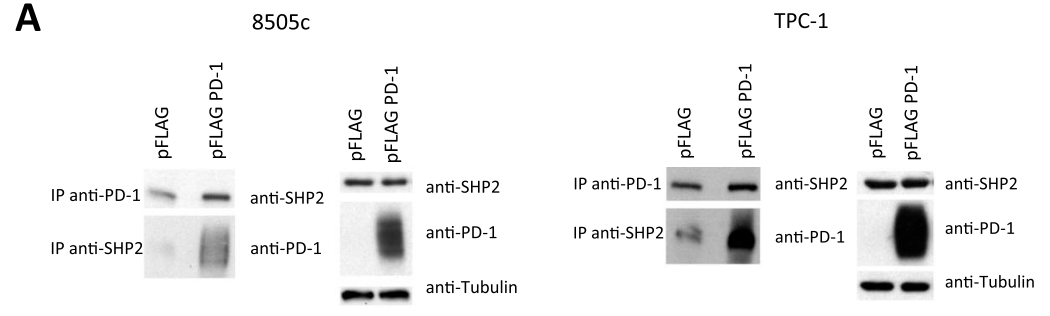

B

$8505 c$

TPC-1
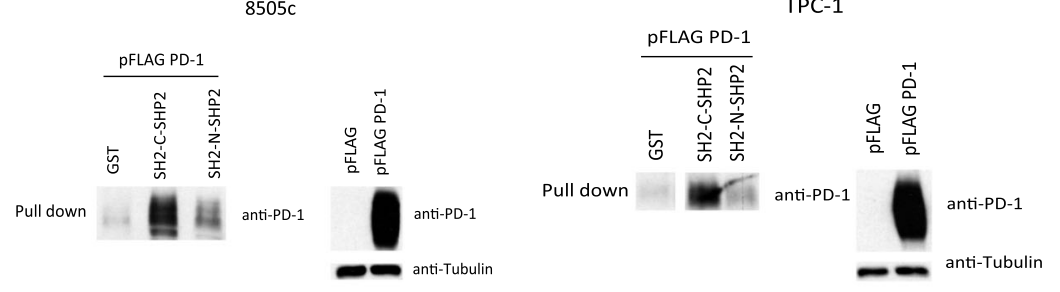

C

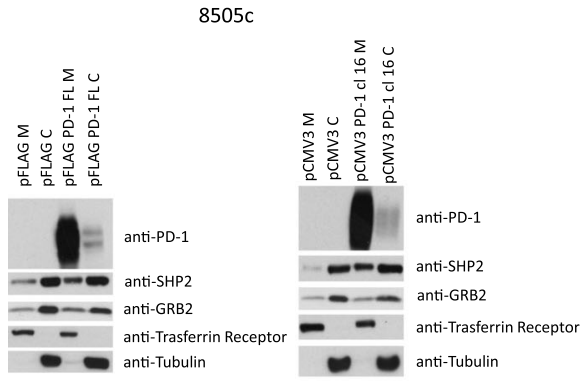

E

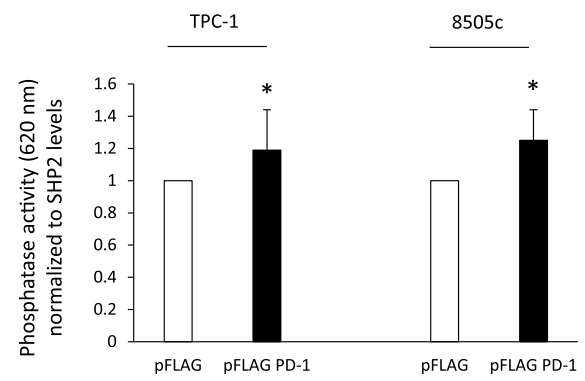

D $\quad$ pFLAG $\quad$ TPC-1 $\quad$ PD-1

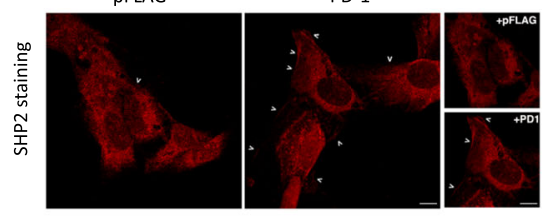

$\mathbf{F}$

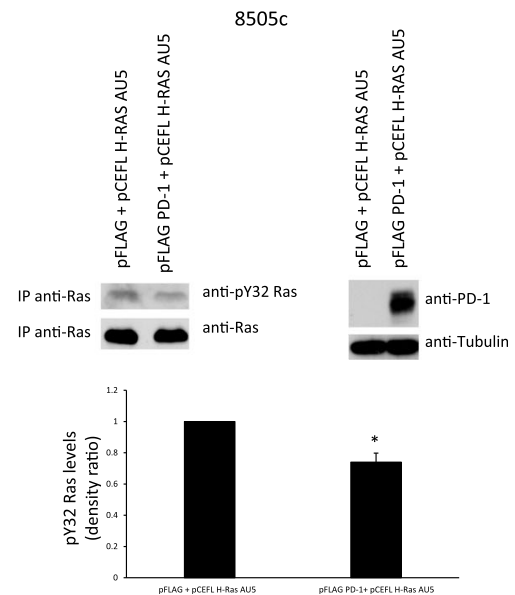

Fig. 4 Effects of intrinsic PD-1 on SHP2 localization and functions. a. Total cell protein extracts from 8505c and TPC-1 cells transiently transfected with pFLAG PD-1 or the empty vector (pFLAG) were subjected to immunoprecipitation followed by western blotting with the indicated antibodies. A representative experiment is shown. $\mathbf{b}$. Total protein extracts from $8505 \mathrm{c}$ and TPC-1 cells transiently transfected with pFLAG-PD-1 were subjected to an in vitro pull-down assay using the indicated recombinant proteins. Bound proteins were immunoblotted with antibody against PD-1. A representative experiment is shown. c. 8505 c cells transiently transfected with PD-1 (pFLAG PD-1) or stably overexpressing PD-1 (pCMV3 PD-1 cl16) and the relative control cells were harvested and subjected to cell protein fractionation. Membrane (M) and cytoplasmic (C) protein fractions were immunoblotted with the indicated antibodies. Transferrin receptor or tubulin levels were used as normalization of membrane and cytosolic fractions, respectively. A representative experiment is shown. $\mathbf{d}$. Immunofluorescence microscopy of TPC-1 cells, transiently transfected with pFLAG PD-1 or the empty vector, stained with an antibody specific for SHP2. A representative experiment is shown. Arrows indicate the surface signal of SHP2. Bars, $5 \mu \mathrm{m}$. e. SHP2 phosphatase activity assay on TPC -1 and $8505 \mathrm{c}$ cells transiently transfected with PD-1 (pFLAG PD-1) and the relative control (pFLAG), assessed by using a specific SHP2 phosphorylated substrate in the presence of the Malachite Green tracer, a colorimetric method (absorbance at $620 \mathrm{~nm}$ ) for the detection of free inorganic phosphate. The SHP2 phosphatase activity was normalized for SHP2 content as assessed by western blot. Data are presented as mean \pm SD of 3 independent experiments. f. Total cell protein extracts from 8505c cells transiently transfected with pCEFL H-Ras AU5 + pFLAG PD-1 or empty vector (pFLAG) were subjected to immunoprecipitation followed by western blotting with the indicated antibodies. A representative experiment is shown, together with the mean densitometric analysis \pm SD of 5 independent assays. ${ }^{*} P<0.05$ compared to the relative control 
in phosphorylation levels of inhibitory residues 64 were observed (not shown).

Taken together, these data indicate that, in TC cells, PD-1 binds SHP2, which in turn dephosphorylates Ras in its inhibitory tyrosine, thus leading to the activation of the MAPK signalling cascade.

\section{PD-1-induced biologic activities in thyroid cancer cells require the SHP2/BRAF/MEK signalling proteins}

To investigate the role of SHP2 in PD-1 functional activity, we treated TC cells, overexpressing or not PD-1, with siRNA targeting SHP2 (siSHP2-100 nM) or with a SHP2 allosteric inhibitor that blocks its phosphatase activity (SHP099-350 nM) [36]. As shown in Fig. 5a, siSHP2 was able to significantly reduce SHP2 protein levels compared to scrambled siRNAs (siCTR). By BrdU incorporation assays, we demonstrated that siSHP2 significantly decreased DNA synthesis (Fig. 5b) in PD-1-, and to a lesser extent in empty vector-transfected, $8505 \mathrm{c}$ cells. Consistently, SHP099 inhibitor significantly reduced PD-1-induced DNA synthesis in 8505c cells (Fig. 5c).

To investigate the role of the downstream signalling cascade in PD-1 dependent biologic TC responses, we conducted BrdU incorporation assays in TC cells overexpressing or not PD-1, in the presence or in the absence of Vemurafenib (Vemu - 10 $1 \mathrm{M}$ ) [37], a BRAF inhibitor, or Selumetinib (Selu - 10 $\mu \mathrm{M}$ ) [38], a MEK inhibitor. As shown in Fig. 5d, both drugs were able to significantly revert PD-1-induced DNA synthesis in $8505 \mathrm{c}$ cells.

Similar experiments were performed to assess the role of the signalling cascade in PD-1-mediated TC cell migration. Figure 5e shows that SHP099 and Vemurafenib, and to a lesser extent Selumetinib, were able to inhibit the migration of $8505 \mathrm{c}$ cells induced by sPD-L1. Similar results were obtained in TC cells transfected with PD-1 (not shown).

These data demonstrate that PD-1-induced cell proliferation and motility of TC cells are dependent on the SHP2/BRAF/MEK pathway.

\section{Intrinsic PD-1 signalling enhances xenograft growth of TC} cells in immunocompromised mice

To verify whether PD-1 intrinsic signalling and biologic activity could affect tumorigenicity of TC cells, we xenotransplanted 8505c pCMV3 PD-1 (two clones) and control 8505c pCMV3 (a mass population) cells in athymic mice. $8505 \mathrm{c}$ pCMV3 PD-1 xenografts displayed increased tumour growth rate that was statistically significant at 4 weeks after injection, in comparison to empty vector transfected cells (Fig. 6a). End-stage tumours were excised and analysed for cell proliferation (Ki-67), apoptotic rate (cleaved-caspase 3) and vessel density
(CD31) by immunohistochemistry. 8505c pCMV3 PD-1 and $8505 \mathrm{c}$ pCMV3 xenografts exhibited statistically significant differences in cell proliferation rate, but not in apoptotic rate or vessel density (Fig. 6b and Suppl. Fig. $5 \mathrm{~A})$.

To verify whether the inhibition of PD-1 by Nivolumab could affect xenograft growth of parental 8505c cells, mice were xenotransplanted, randomized in two homogeneous groups, and administered intraperitoneally (i.p.) with Nivolumab (Nivo) or control $\mathrm{IgG}_{4}(30 \mathrm{mg} / \mathrm{kg})$ twice a week. 5 weeks after xenotransplantation, Nivolumab-treated tumours showed a significant decrease in growth rate in comparison with the $\mathrm{IgG}_{4}$ treated group (Fig. 6c). Consistently, Nivolumab significantly reduced TC xenografts' proliferation without affecting apoptotic rate or vessel density (Fig. 6d and Suppl. Fig. 5B).

Despite these experiments were carried out in immunocompromised mice, we could not exclude that Nivolumab anti-tumour activity could be ascribed to its ability to affect innate immunity that is present and functional in athymic mice. Thus, we analysed the density and activation of immune cells infiltrating $8505 \mathrm{c}$ xenografts treated with Nivolumab or with $\operatorname{IgG}_{4}$ by cytofluorimetric analysis. We found that Nivolumab treatment did not change the percentage of $\mathrm{CD} 45^{+}$leucocytes infiltrating xenografts in comparison to $\mathrm{IgG}_{4}$ controls, at least at 5 weeks of treatment. Moreover, the density and the expression of polarization/activation markers of tumour-associated macrophages (TAM), of Ly6C $\mathrm{C}^{+}$and $\mathrm{Ly}_{6 \mathrm{G}}{ }^{+}$immature myeloid cells, of mature and immature dendritic cells and of regulatory or activated NK, and NKT cells, were comparable between Nivolumab- and $\mathrm{IgG}_{4}$-treated $8505 \mathrm{c}$ xenografts (Suppl. Table 1).

These data indicate that, in our model system, PD-1 blockade by Nivolumab inhibits TC cell xenograft growth by affecting tumour cell rather than immune cell compartment.

\section{Discussion}

Several reports point to a promising role of immunotherapy in the treatment of advanced forms of TCs $[15,39]$. TCGA analysis of TC provided a classification of PTC, in spite of their low mutational burden, as "inflamed" tumours and ATC as hot tumours [40]. Interestingly, a profiling of TC confirmed that ATC and PTC are strongly infiltrated by macrophages and $\mathrm{CD}^{+} \mathrm{T}$ cells, but that these cells displayed a functionally exhausted appearance [11]. In TC, high PDL1 levels significantly correlated with immune infiltrate, increased tumour size and multifocality $[17,18]$. Furthermore, the presence of PD- $1^{+} \mathrm{T}$ lymphocyte infiltrating $\mathrm{TC}$ is associated with lymph-nodal 

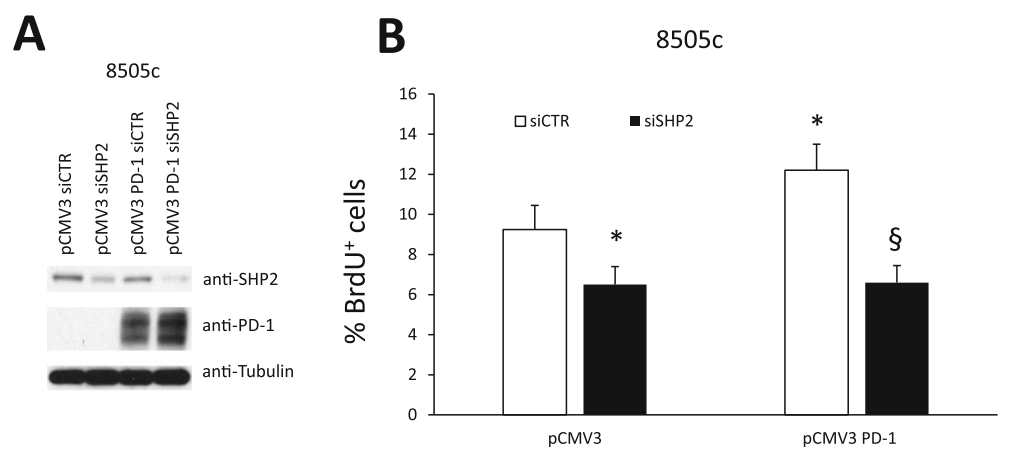

C $8505 c$

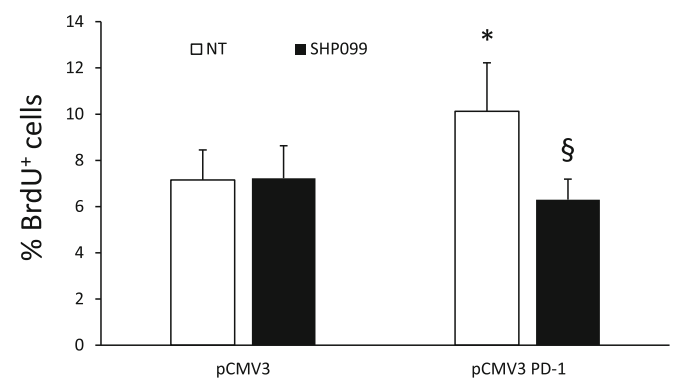

D $8505 c$

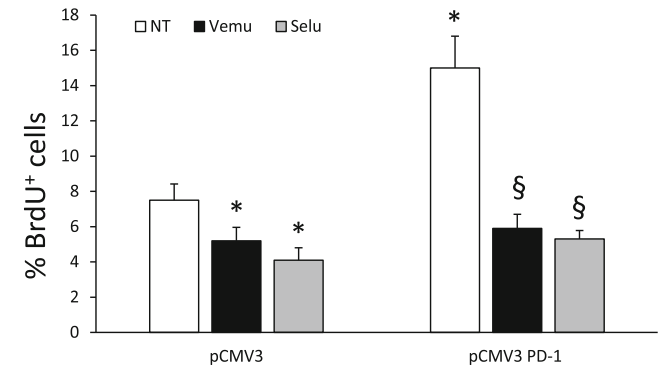

E

$8505 c$

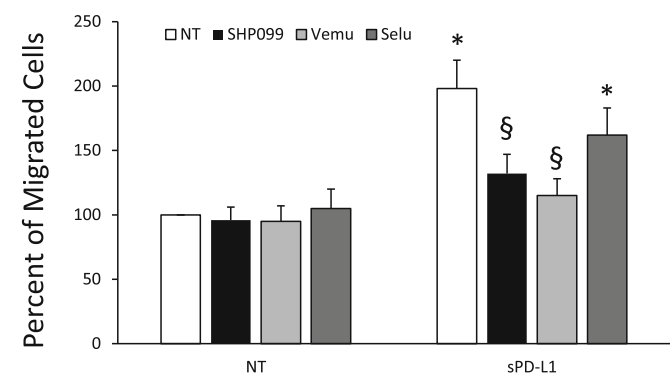

Fig. 5 (See legend on next page.) 
(See figure on previous page.)

Fig. 5 Dependence of PD-1 biologic activities on SHP2/BRAF/MEK cascade. a. Effects of siRNA targeting SHP2 (siSHP2-100 nM) or the relative control on SHP2 protein expression levels assessed by western blot in $8505 \mathrm{c}$ cells stably transfected with PD-1 or the empty vector (one representative clone is shown). b. DNA synthesis of stably transfected 8505c pCMV3 PD-1 cells (mean of 3 clones) compared to empty vector transfected cells treated with siSHP2 or siCTR assessed by BrdU incorporation. Data are presented as mean \pm SD of 5 independent experiments. c. DNA synthesis of 8505c cells stably transfected with PD-1 (pCMV3 PD-1 compared to pCMV3) and treated for $18 \mathrm{~h}$ with SHP099 (350 nM) assessed by BrdU incorporation. The mean of 3 clones is shown for each condition. Data are presented as mean \pm SD of 5 independent experiments. $\mathbf{d}$. DNA synthesis of stably transfected 8505c pCMV3 PD-1 cells (3 clones) compared to empty vector transfected cells treated for $18 \mathrm{~h}$ with Vemurafenib (Vemu - $10 \mu \mathrm{M})$ or Selumetinib (Selu - $10 \mu \mathrm{M})$ assessed by BrdU incorporation. Data are presented as mean \pm SD of 5 independent experiments. e. Percent of migrated $8505 \mathrm{c}$ cells over control toward SPD-L1 $(1 \mu \mathrm{g} / \mathrm{ml})$ or medium alone (10\% FBS) following treatment with SHP099 (350 nM), Vemurafenib (Vemu - $10 \mu \mathrm{M})$ or Selumetinib (Selu - $10 \mu \mathrm{M})$. Data are presented as mean \pm SD of 5 independent experiments. * $P<0.05$ compared to the relative control. $\S P<0.05$ compared to NT or siCTR

metastasis and recurrence [13]. Altogether, these data suggest that immune checkpoint inhibitors (ICI) might represent a promising tool for the treatment of these carcinomas.

Our report, for the first time, investigated the expression of the PD-1 receptor in epithelial thyroid cancer cells, demonstrating that a significant percentage of human TC samples displayed PD-1 expression on these cells, although at lower levels compared to the expression found on immune cells infiltrating the tumour. Consistently with the evidence obtained for PD-L1 [17, 41], our data indicate that PD-1 expression levels correlated with tumour stage and lymph-nodal metastasis in TC. Accordingly, we demonstrated that PD-1 activity could induce proliferation and motility of TC cells in culture. This suggests that the PD-1 intrinsic pathway might have a role in TC cell aggressiveness and invasive ability.

The expression of PD-1 on cancer cells, rather than on immune cells, has been observed recently in melanoma and hepatocellular carcinoma (HCC) $[5,6,42]$ where PD-1 exerts a tumor promoting function. On the other hand, the intrinsic PD-1 expression in non-small cell lung cancer (NSCLC) has been described to exert a

\section{A}

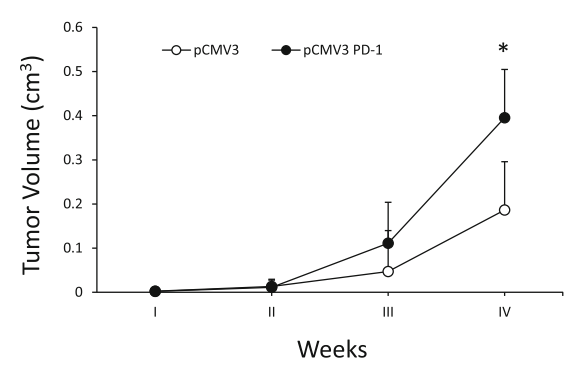

C

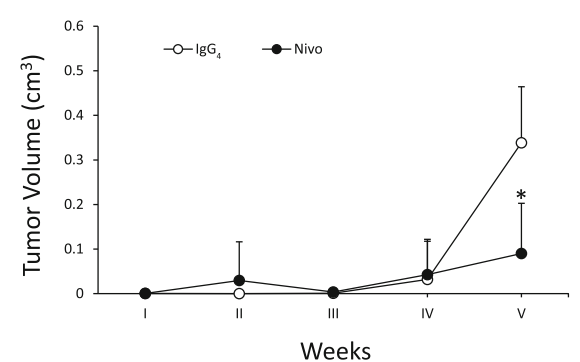

B

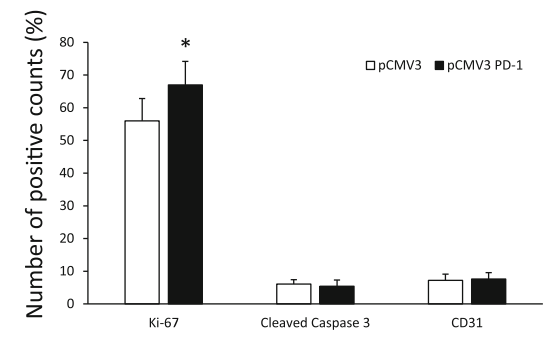

D

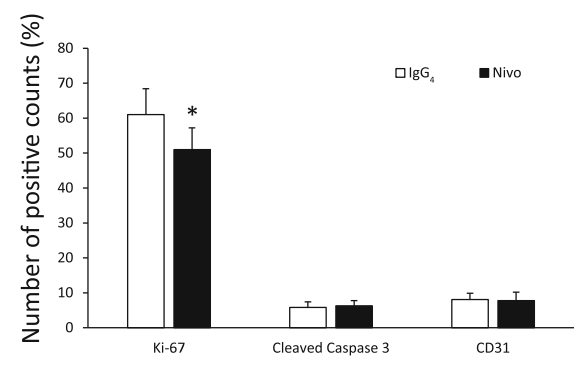

Fig. 6 Role of intrinsic PD-1 in tumorigenicity of TC cells. a. Tumour growth of pCMV3- (a mass population) or PD-1-transfected (mean of 2 clones) 8505c cells. b. Proliferation index (Ki-67), apoptotic rate (cleaved caspase 3), and vessel density (CD31) assessed by immunohistochemistry of 8505 c pCMV3 or pCMV3 PD-1 cell xenografts harvested 28 days post-inoculation. The relative quantifications (5 fields/sample) are shown. c. Tumour growth of 8505 c xenografts in mice treated intraperitoneally (i.p.) at 30 mg/kg twice per week with Nivolumab (Nivo) or control lgG. d. Proliferation index (Ki-67), apoptotic rate (cleaved caspase 3), and vessel density (CD31) assessed by immunohistochemistry of $8505 \mathrm{c}$ cell xenografts, treated with Nivoumab or $\operatorname{lgG}_{4}$, harvested 35 days post-inoculation. The relative quantifications (5 fields/sample) are shown.* $P<0.05$ compared to the relative control 
tumor suppressor role and to represent a potential mechanism by which PD-1 blockade may promote cancer growth $[7,42]$.

In melanoma and HCC, intrinsic PD- 1 activity sustains tumour growth through an mTOR/S6K1 signalling $[5,6$, 42]. In TC cells, similarly to melanoma and HCC, PD-1 intrinsic signalling sustains cancer cell proliferation, but at variance from these neoplasias, this biologic activity is mediated by the activation of the Ras/MAPK pathway. Interestingly, mutations causing the activation of the Ras/MAPK signalling pathway are found in $>70 \%$ of PTC (e.g., RET/PTC rearrangements and point mutations of the BRAF and Ras genes) and regulate transcription of key genes involved in TC cell proliferation [43]. PD-1 expression could provide a selective advantage to some TC by enhancing the activation of MAPK pathway, thus promoting proliferation and migratory behaviour of cancer cells. Interestingly, besides PD-1, also the immune-checkpoint Cytotoxic $\mathrm{T}$ lymphocyte-associated antigen 4 (CTLA-4), classically expressed on leukocytes, has been found to be expressed and functional on cancer cells $[44,45]$.

Our data also highlighted the key role of the SHP2 tyrosine-phosphatase in PD-1-mediated activities in TC cells. Interestingly, SHP2 is recruited by PD-1 in T lymphocytes, and inhibits immune receptor signalling by dephosphorylating several downstream substrates [31, 46]. In cancer cells, SHP2 has been described to exhibit oncogenic properties [32, 33]. SHP2 functions as an adapter that binds activated receptor tyrosine kinases (RTKs) and recruits the GRB2/SOS complex on the plasma membrane, enhancing SOS-mediated GTP loading on Ras and activating the Ras/MAPK cascade [32, 33]. SHP2 can also directly enhance Ras activity by dephosphorylating specific inhibitory tyrosine residues on Ras [29, 35, 47]. In our model system, we found that PD-1 exploits this last mechanism. However, we cannot exclude that other PD-1 functions may contribute to Ras/MAPK activation. Whatever the case, we demonstrated that, in TC cells, SHP2 is a critical factor in PD-1 downstream signalling, as SHP2 inhibition hampered PD-1-mediated biological activities.

The majority of TC are driven by mutations that activate the Ras/MAPK pathway. Inhibitors targeting different proteins in this signalling cascade have been developed, but their efficacy has been limited by adaptive feedback reactivation of the pathway [48]. Interestingly, SHP2 has been identified as one of the main mediators of adaptive resistance to inhibitors of the Ras/MAPK pathway in many tumors, including TC. In 8505c cells, carrying a BRAF(V600E) mutation, targeting both BRAF and SHP2 with Vemurafenib and SHP099 led to a reversion of adaptive resistance to either inhibitor alone [49, 50]. Furthermore, in TC samples, increased SHP2 expression was detected compared to normal thyroids, and this correlated with poor tumour differentiation, TNM stage and lymph-nodal metastasis [51]. These evidences suggest that SHP2 may represent a potential target for TC therapy both alone and in combination with PD-1 and/or Ras/MAPK targeting.

The evaluation of PD-1 expression in cancer cell might be important to identify tumours and/or patients that will be likely to respond to ICI administration by taking advantage of both drug effects on immune compartment and on cancer cell proliferation. In few case reports or in "basket clinical trials" in which ICI [i.e., Pembrolizumab (anti-PD-1), Nivolumab (anti-PD-1), or Atezolizumab (anti-PD-L1)] were used alone or in combination with Multikinase Inhibitors (MKI) for the treatment of advanced and/or metastatic TC, encouraging preliminary clinic evidence of efficacy has been reported $[9,52,53]$.

\section{Conclusions}

Our observations demonstrate that PD-1 is expressed on TC cells and exerts an intrinsic pro-tumorigenic function. Thus TC, and possibly other cancer types, could benefit of the dual effects of ICI: the reactivation of immune anti-tumour response and the direct antiproliferative effects on cancer cells. Defining the functional and biochemical activity of immune checkpoints both in cancerous cells and in tumour microenvironment of TC will expand our knowledge allowing to develop rational therapeutic strategies for aggressive TC exploiting ICI in combination with SHP2 or RTK/Ras/ MAPK inhibitors.

\section{Supplementary Information}

The online version contains supplementary material available at https://doi. org/10.1186/s13046-020-01818-1.

Additional file 1: Supplementary Table 1. Mouse immune cell density (expressed as percentage of CD45 ${ }^{+}$leukocytes) in $8505 \mathrm{c}$ xenografts.

Additional file 2: Supplementary Figure 1. Immune checkpoint expression in thyroid cancer (TC) cells. Protein expression levels assessed by western blot (A) and mRNA expression indicated as $\triangle C$ t for PD-1, PDL1 and PD-L2 (B) in H-6040 normal thyroid epithelial cells, PTC-derived cell lines (BCPAP and TPC-1), and ATC-derived cell lines (8505C, CAL62, SW1736, FRO, BHT101, HTH7, OCUT1). A representative western blot experiment is shown. PCR data are presented as mean \pm SD of 5 independent experiments.

Additional file 3: Supplementary Figure 2. Functional activity of intrinsic PD-1 circuit in TC cells. A. Expression levels of PD-1 in 8505c and TPC1 cells or in $8505 \mathrm{C}$ and TPC-1 transiently transfected with PFLAG or pFLAG PD-1, assessed by western blot. A representative experiment is shown. B. Cell cycle distribution of $8505 \mathrm{C}$ and TPC-1 cells transiently transfected with pFLAG or pFLAG PD-1, measured by Propidium lodide (PI) staining by means of Flow Cytometry. The percent of the cells distributed in G0/G1, S, G2/M was indicated in each panel. Representative experiments are shown. C. Percent of apoptotic cells assessed by TUNEL reaction in $8505 \mathrm{c}$ and TPC-1 cells transiently transfected with PFLAG or pFLAG PD-1 and treated or not with soluble PD-L1 (sPD-L1 - 1 mg/ml). Data are presented as mean \pm SD of 5 independent experiments. $\mathbf{D}$. 
Cytofluorimetric evaluation of PD-1 expression in 8505c cells treated with siPD-1 (solid lines) or scrambled siCTR (dotted line) (100 nM). A representative experiment is shown. E. Cell cycle distribution of $8505 \mathrm{C}$ and TPC-1 cells treated with Nivolumab (Nivo $-10 \mu \mathrm{g} / \mathrm{ml})$ or control $\operatorname{lgG}_{4}(10 \mu \mathrm{g} / \mathrm{ml})$, measured by Propidium lodide (PI) staining by means of Flow Cytometry. The percent of the cells distributed in G0/G1, S, G2/M was indicated in each panel. Representative experiments are shown. F. Percent of apoptotic cells assessed by TUNEL reaction in $8505 \mathrm{C}$ and TPC-1 cells treated with siPD-1 (100 nM) or Nivolumab (Nivo $-10 \mu \mathrm{g} / \mathrm{ml}$ ) or the relative controls. Data are presented as mean \pm SD of 5 independent experiments. G. DNA synthesis of $8505 \mathrm{c}$ cells transiently transfected with pCMV3, PCMV3 PD-L1 or PCMV3 PD-L2 or treated with anti-PD-L1, anti-PD-L2 blocking antibodies or $\mathrm{lgG}_{1}$ isotype control $(10 \mu \mathrm{g} / \mathrm{ml})$ assessed by BrdU incorporation. Data are presented as mean \pm SD of 5 independent experiments. ${ }^{*} P<0.05$ compared to the relative control.

Additional file 4: Supplementary Figure 3. Signalling pathways downstream PD-1overexpression. A. Expression levels of PD-1 in some clones or mass populations obtained from $8505 \mathrm{c}$ cells stably transfection with PD-1, assessed by western blot. A representative experiment is shown. B. Expression levels of phosphorylated forms of BRAF, MEK1/2 and MAPK (p44/p42) in 8505c cells stably transfected with PD-1 or the empty vector, assessed by western blot. A representative experiment is shown. C. Activation of AKT, SRC, S6, S6K, 4EBP1 in 8505C and TPC-1 cells, transiently transfected or not with PD-1 or the relative empty vector, assessed by western blot for their phosphorylated forms. A representative experiment is shown.

Additional file 5: Supplementary Figure 4. Effects of intrinsic PD-1 on SHP2 localization and functions. A. Expression levels of PD-1, phospho-PD-1, SHP2 and phospho-SHP2 in 8505c and TPC-1 cells transiently transfected with pFLAG PD-1 or the empty vector pFLAG, assessed by western blot. A representative experiment is shown. B. Immunofluorescence microscopy of $8505 \mathrm{c}$ cells, transiently transfected with pFLAG PD-1 or the empty vector, with antibody specific for SHP2. Arrows indicate the surface signal of SHP2. Bars, $5 \mu \mathrm{m}$. A representative experiment is shown. C. Immunofluorescence microscopy of 8505 c cells transiently transfected with pCMV6 PD-1-GFP and stained with antibody specific for SHP2, and the merged signal. Arrows indicate the surface signal of SHP2. Bars, $5 \mu \mathrm{m}$. A representative experiment is shown. D. Total protein extracts from TPC-1 cells transiently transfected with pFLAG-PD-1 or the empty vector pFLAG were subjected to a pull-down assay using the indicated recombinant proteins or to immunoprecipitation using the indicated antibodies. Proteins were immunoblotted with antibody against SHP2 or GRB2. A representative experiment is shown. E. Total cell protein extracts from $8505 \mathrm{c}$ cells transiently transfected with combination of pCEFL H-Ras AU5, pFLAG PD-1 or empty vector (pFLAG + pCEFL) were subjected to immunoprecipitation with anti-phospho tyrosine followed by western blotting with pan (RAS) antibody. A representative experiment is shown, together with the mean densitometric analysis \pm SD of 5 independent assays. ${ }^{*} \mathrm{P}<0.05$ compared to the relative control.

Additional file 6: Supplementary Figure 5. Immunohistochemical evaluation of $8505 \mathrm{c}$ xenografts. A. Proliferation index (Ki-67) assessed by immunohistochemistry of 8505 c pCMV3 and pCMV3 PD-1 cl13 xenografts harvested 28 days post-inoculation. Representative images are shown. B. Proliferation index (Ki-67) assessed by immunohistochemistry of $8505 \mathrm{C}$ xenografts harvested 35 days post-inoculation in mice treated with Nivolumab or control $\operatorname{lgG}_{4}$. Representative images are shown.

\section{Abbreviations}

PD-L1: Programmed cell death-ligand 1; PD-L2: Programmed cell deathligand 2; IC: Immune checkpoints; PD-1: Programmed cell death-1; ICl: Immune checkpoint inhibitors; moAb: Monoclonal antibody; mTOR: Mammalian target of rapamycin; S6K1: Ribosomal protein S6 kinase; NSCLS: Non-small cell lung cancer; TC: Thyroid carcinoma; WDTC: Well differentiated thyroid carcinoma; PDTC: Poorly differentiated thyroid carcinoma; ATC: Anaplastic thyroid carcinoma; PTC: Papillary thyroid carcinoma; FTC: Follicular thyroid carcinoma; RAl: Radioactive iodine I-131; SHP-2: Src homology 2 (SH2)-containing protein tyrosine phosphatase 2; RAS: Rat sarcoma; MAPK: Mitogen-activated protein kinases; FBS: Fetal bovine serum; BRAF: Serine/threonine-protein kinase B-raf; MEK1/2: Mitogen- activated protein kinase kinase 1; GRB2: Growth factor receptor bound protein 2; GST: Glutathione S-transferase; SDS-PAGE: Sulphate-polyacrylamide gel electrophoresis; ECL: Enhanced chemiluminescence; PBS: Phosphate buffered saline; PFA: Paraformaldehyde; BSA: Bovine serum albumin; IgG: Immunoglobulin $\mathrm{G}_{4}$; Ki-67: Marker of proliferation Ki-67; CD31: Cluster of differentiation 31; SEM: Standard error of the mean;

IHC: Immunohistochemistry; SPD-L1: Soluble PD-L1; siRNA: Small interfering RNA; BrdU: Bromodeoxyuridine; Src: Proto-oncogene tyrosine-protein kinase Src; S6: Ribosomal protein S6; AKT: Protein kinase B; 4EBP1: Eukaryotic translation initiation factor $4 \mathrm{E}-$ binding protein 1; RBD: Ras binding domain; PTPN11: Tyrosine-protein phosphatase non-receptor type 11; SOS: Son of sevenless; GTP: Guanosine triphosphate; TAM: Tumour associated macrophages; Ly $6 C^{+}$: Lymphocyte antigen $6 C_{;}$Ly $6 G^{+}$: Lymphocyte antigen 6G; NK: Natural killer; NKT: Natural killer T; HCC: Hepatocellular carcinoma; CTLA-4: Cytotoxic T lymphocyte-associated antigen 4; RET: Proto-oncogene tyrosine-protein kinase receptor Ret; TNM: Tumour-nodes-metastasis; MKI: Multi-kinase inhibitors

\section{Acknowledgements}

We are grateful to Rosaria Catalano and Mariarosaria Montagna for technical help, and Massimiliano Cacace for animal handling.

\section{Authors' contributions}

F.L. participated in the design of the study, carried out in vitro and in vivo experiments, drafted the manuscript, read and approved this manuscript; N.K., N.P., M.M., D.S., A.R., F.Z.M. and S.P. carried out in vitro or in vivo experiments, read and approved this manuscript; S.M., R.C., and E.P. carried out immunohistochemistry, read and approved this manuscript; Y.K. and M.O. provided anti-phospho Y32, anti-phospho Y64 Ras antibodies and Y32 and Y64 peptides, participated in conception and design of experiments, read and approved this manuscript; C.I. and S.S. provided Nivolumab participated in conception and design of experiments, read and approved this manuscript; R.M.M. conception and design, data analysis and interpretation, manuscript writing, final approval of manuscript, and financial support.

\section{Funding}

Associazione Italiana per la Ricerca sul Cancro (AIRC) IG grant 23218; Istituto Superiore di Oncologia grant (MIUR PON01_02782/12); POR Campania FESR 2014-2020 "SATIN" grant; POR Campania FESR 2014-2020 "RARE.PLAT.NET" grant.

\section{Availability of data and materials}

All data generated or analysed during this study are included within the article or available from the corresponding author on reasonable request.

\section{Ethics approval and consent to participate}

The experimental protocol for animal studies was reviewed and approved by the Ministero Italiano della Salute and the institutional committee of University of Naples Federico II. Thyroid carcinomas were selected from the Pathology Unit of the University of Perugia upon informed consent, the protocol for the study was approved by the institutional committee of University of Perugia.

\section{Consent for publication}

All authors agreed on the manuscript.

\section{Competing interests}

The authors declare no conflict of interest.

\section{Author details}

${ }^{1}$ Institute of Experimental Endocrinology and Oncology (IEOS), CNR, Naples, Italy. ${ }^{2}$ Department of Translational Medical Sciences, University of Naples Federico II, Naples, Italy. ${ }^{3}$ Department of Molecular Medicine and Medical Biotechnology, University of Naples Federico II, Via S. Pansini 5, 80131 Naples, Italy. ${ }^{4}$ Department of Advanced Biomedical Sciences, University of Naples Federico II, Naples, Italy. ${ }^{5}$ Functional Genomics, Istituto Nazionale Tumouri "Fondazione G. Pascale", IRCCS, Naples, Italy. ${ }^{6}$ Department of Mental and Physical Health and Preventive Medicine, University of Campania "Luigi Vanvitelli", Naples, Italy. 'Department of Medicine, University of Perugia, Perugia, Italy. ${ }^{8}$ Department of Experimental Medicine, University of Perugia, Perugia, Italy. ${ }^{9}$ Department of Clinical Oncology, Graduate School of Medical 
and Dental Sciences, Tokyo Medical and Dental University, Tokyo, Japan. ${ }^{10}$ Department of Laboratory Medicine and Pathobiology, University of Toronto, Toronto, Canada. " Department of Biochemistry Faculty of Medicine, University of Toronto, Toronto, Canada.

\section{Received: 23 October 2020 Accepted: 15 December 2020}

Published online: 07 January 2021

\section{References}

1. Yang Y. Cancer immunotherapy: harnessing the immune system to battle cancer. J Clin Invest. 2015;125:3335-7.

2. Kruger $\mathrm{S}$, Ilmer M, Kobold S, Cadilha BL, Endres S, Ormanns $\mathrm{S}$, et al. Advances in cancer immunotherapy 2019 - latest trends. J Exp Clin Cance Res. 2019;38:268

3. Rabinovich GA, Gabrilovich D, Sotomayor EM. Immunosuppressive strategies that are mediated by tumor cells. Annu Rev Immunol. 2007;25:267-96.

4. McNutt M. Cancer immunotherapy. Science. 2013;342:1417.

5. Kleffel S, Posch C, Barthel SR, Mueller H, Schlapbach C, Guenova E, et al. Melanoma cell-intrinsic PD-1 receptor functions promote tumor growth. Cell. 2015;162:1242-56.

6. Li H, Li X, Liu S, Guo L, Zhang B, Zhang J, et al. Programmed cell death-1 (PD-1) checkpoint blockade in combination with a mammalian target of rapamycin inhibitor restrains hepatocellular carcinoma growth induced by hepatoma cell-intrinsic PD-1. Hepatology. 2017;66:1920-33.

7. Du S, McCall N, Park K, Guan Q, Fontina P, Ertel A, et al. Blockade of tumorexpressed PD-1 promotes lung cancer growth. Oncoimmunology. 2018;7: e1408747.

8. Zhao Y, Harrison DL, Song Y, Ji J, Huang J, Hui E. Antigen-presenting cellintrinsic PD-1 neutralizes PD-L1 in cis to attenuate PD-1 signaling in T cells. Cell Rep. 2018;24:379-90 e6.

9. Liotti F, Prevete N, Vecchio G, Melillo RM. Recent advances in understanding immune phenotypes of thyroid carcinomas: prognostication and emerging therapies. F1000 Faculty Rev. 2019;8:227.

10. Naoum GE, Morkos M, Kim B, Arafat W. Novel targeted therapies and immunotherapy for advanced thyroid cancers. Mol Cancer. 2018;17:51.

11. Giannini R, Moretti S, Ugolini C, Macerola E, Menicali E, Nucci N, et al. Immune profiling of thyroid carcinomas suggests the existence of two major phenotypes: an ATC-like and a PDTC-like. J Clin Endocrinol Metab. 2019;104:3557-75

12. Bastman JJ, Serracino HS, Zhu Y, Koenig MR, Mateescu V, Sams SB, et al. Tumor-infiltrating $T$ cells and the PD-1 checkpoint pathway in advanced differentiated and anaplastic thyroid Cancer. J Clin Endocrinol Metab. 2016; 101:2863-73.

13. French JD, Kotnis GR, Said S, Raeburn CD, Mclntyre RC Jr, Klopper JP, et al. Programmed death-1+ T cells and regulatory $T$ cells are enriched in tumorinvolved lymph nodes and associated with aggressive features in papillary thyroid cancer. J Clin Endocrinol Metab. 2012;97:E934-43.

14. Malfitano AM, Somma SD, Prevete N, Portella G. Virotherapy as a potential therapeutic approach for the treatment of aggressive thyroid Cancer. Cancers. 2019;11:1532-53.

15. Saini S, Tulla K, Maker AV, Burman KD, Prabhakar BS. Therapeutic advances in anaplastic thyroid cancer: a current perspective. Mol Cancer. 2018;17:154.

16. Ulisse S, Tuccilli C, Sorrenti S, Antonelli A, Fallahi P, D'Armiento E, et al. PD-1 ligand expression in epithelial thyroid cancers: potential clinical implications. Int J Mol Sci. 2019:20:1405-20.

17. Cunha LL, Morari EC, Guihen AC, Razolli D, Gerhard R, Nonogaki S, et al. Infiltration of a mixture of immune cells may be related to good prognosis in patients with differentiated thyroid carcinoma. Clin Endocrinol. 2012;77: 918-25.

18. Cunha LL, Marcello MA, Morari EC, Nonogaki S, Conte FF, Gerhard R, et al. Differentiated thyroid carcinomas may elude the immune system by $\mathrm{B} 7 \mathrm{H} 1$ upregulation. Endocr Relat Cancer. 2013;20:103-10.

19. De Falco V, Castellone MD, De Vita G, Cirafici AM, Hershman JM, Guerrero C, et al. RET/papillary thyroid carcinoma oncogenic signaling through the Rap1 small GTPase. Cancer Res. 2007;67:381-90.

20. Liotti F, Collina F, Pone E, La Sala L, Franco R, Prevete N, et al. Interleukin-8, but not the related chemokine CXCL1, sustains an Autocrine circuit necessary for the properties and functions of thyroid Cancer stem cells. Stem Cells. 2017:35:135-46.

21. Prevete $\mathrm{N}$, Liotti F, Illiano A, Amoresano A, Pucci P, de Paulis A, et al. Formyl peptide receptor 1 suppresses gastric cancer angiogenesis and growth by exploiting inflammation resolution pathways. Oncoimmunology. 2017;6: e1293213.

22. Prevete N, Liotti F, Visciano C, Marone G, Melillo RM, de Paulis A. The formyl peptide receptor 1 exerts a tumor suppressor function in human gastric cancer by inhibiting angiogenesis. Oncogene. 2015;34:3826-38.

23. Paulsen EE, Kilvaer TK, Khanehkenari MR, Al-Saad S, Hald SM, Andersen S, et al. Assessing PDL-1 and PD-1 in non-small cell lung Cancer: a novel Immunoscore approach. Clin Lung Cancer. 2017;18:220-33 e8.

24. Kouketsu A, Sato I, Oikawa M, Shimizu Y, Saito H, Takahashi T, et al. Expression of immunoregulatory molecules PD-L1 and PD-1 in oral cancer and precancerous lesions: a cohort study of Japanese patients. J Cranio Maxillo Facial Surg. 2019;47:33-40.

25. Liotti F, De Pizzol M, Allegretti M, Prevete N, Melillo RM. Multiple anti-tumor effects of Reparixin on thyroid cancer. Oncotarget. 2017:8:35946-61.

26. Collina F, La Sala L, Liotti F, Prevete N, La Mantia E, Chiofalo MG, et al. AXL is a novel predictive factor and therapeutic target for radioactive iodine refractory thyroid Cancer. Cancers. 2019;11:785-805.

27. Avilla E, Guarino V, Visciano C, Liotti F, Svelto M, Krishnamoorthy G, et al. Activation of TYRO3/AXL tyrosine kinase receptors in thyroid cancer. Cancer Res. 2011;71:1792-804

28. Paladino S, Lebreton S, Tivodar S, Campana V, Tempre R, Zurzolo C. Different GPI-attachment signals affect the oligomerisation of GPI-anchored proteins and their apical sorting. J Cell Sci. 2008;121:4001-7.

29. Bunda S, Burrell K, Heir P, Zeng L, Alamsahebpour A, Kano Y, et al. Inhibition of SHP2-mediated dephosphorylation of Ras suppresses oncogenesis. Nat Commun. 2015;6:8859.

30. Knauf JA, Fagin JA. Role of MAPK pathway oncoproteins in thyroid cancer pathogenesis and as drug targets. Curr Opin Cell Biol. 2009;21:296-303.

31. Rota G, Niogret C, Dang AT, Barros CR, Fonta NP, Alfei F, et al. Shp-2 is dispensable for establishing $T$ cell exhaustion and for PD-1 signaling in vivo. Cell Rep. 2018;23:39-49.

32. Zhang J, Zhang F, Niu R. Functions of Shp2 in cancer. J Cell Mol Med. 2015; 19:2075-83.

33. Ran H, Tsutsumi R, Araki T, Neel BG. Sticking it to Cancer with molecular glue for SHP2. Cancer Cell. 2016;30:194-6.

34. Matozaki T, Murata $Y$, Saito $Y$, Okazawa $H$, Ohnishi $H$. Protein tyrosine phosphatase SHP-2: a proto-oncogene product that promotes Ras activation. Cancer Sci. 2009;100:1786-93.

35. Kano Y, Cook JD, Lee JE, Ohh M. New structural and functional insight into the regulation of Ras. Semin Cell Dev Biol. 2016;58:70-8.

36. Chen YN, LaMarche MJ, Chan HM, Fekkes P, Garcia-Fortanet J, Acker MG, et al. Allosteric inhibition of SHP2 phosphatase inhibits cancers driven by receptor tyrosine kinases. Nature. 2016;535:148-52.

37. Xing J, Liu R, Xing M, Trink B. The BRAFT1799A mutation confers sensitivity of thyroid cancer cells to the BRAFV600E inhibitor PLX4032 (RG7204). Biochem Biophys Res Commun. 2011;404:958-62.

38. Ball DW, Jin N, Rosen DM, Dackiw A, Sidransky D, Xing M, et al. Selective growth inhibition in BRAF mutant thyroid cancer by the mitogen-activated protein kinase kinase 1/2 inhibitor AZD6244. J Clin Endocrinol Metab. 2007: 92:4712-8.

39. Boutros $\mathrm{C}$, Tarhini A, Routier $\mathrm{E}$, Lambotte $\mathrm{O}$, Ladurie FL, Carbonnel $\mathrm{F}$, et al. Safety profiles of anti-CTLA-4 and anti-PD-1 antibodies alone and in combination. Nat Rev Clin Oncol. 2016:13:473-86.

40. Thorsson V, Gibbs DL, Brown SD, Wolf D, Bortone DS, Ou Yang TH, et al. The immune landscape of Cancer. Immunity. 2018;48:812-30 e14.

41. Cunha LL, Marcello MA, Vassallo J, Ward LS. Differentiated thyroid carcinomas and their B7H1 shield. Future Oncol. 2013;9:1417-9.

42. Yao H, Wang H, Li C, Fang JY, Xu J. Cancer cell-intrinsic PD-1 and implications in combinatorial immunotherapy. Front Immunol. 2018;9:1774.

43. Nikiforov YE. Thyroid carcinoma: molecular pathways and therapeutic targets. Mod Pathol. 2008;21(Suppl 2):S37-43.

44. Passariello M, Camorani S, Vetrei C, Ricci S, Cerchia L, De Lorenzo C. Ipilimumab and its derived EGFR Aptamer-based conjugate induce efficient NK cell activation against Cancer cells. Cancers. 2020;12:331-49.

45. Contardi E, Palmisano GL, Tazzari PL, Martelli AM, Fala F, Fabbi M, et al. CTLA-4 is constitutively expressed on tumor cells and can trigger apoptosis upon ligand interaction. Int J Cancer. 2005;117:538-50.

46. Rotte A Combination of CTLA-4 and PD-1 blockers for treatment of cancer. J Exp Clin Cancer Res. 2019;38:255.

47. Scott LM, Chen L, Daniel KG, Brooks WH, Guida WC, Lawrence HR, et al. Shp2 protein tyrosine phosphatase inhibitor activity of estramustine 
phosphate and its triterpenoid analogs. Bioorg Med Chem Lett. 2011;21: 730-3.

48. Seebacher NA, Stacy AE, Porter GM, Merlot AM. Clinical development of targeted and immune based anti-cancer therapies. J Exp Clin Cancer Res. 2019;38:156.

49. Ahmed TA, Adamopoulos C, Karoulia Z, Wu X, Sachidanandam R, Aaronson SA, et al. SHP2 drives adaptive resistance to ERK signaling inhibition in molecularly defined subsets of ERK-dependent tumors. Cell Rep. 2019;26:6578 e5.

50. Yaeger R, Corcoran RB. Targeting alterations in the RAF-MEK pathway. Cancer Discov. 2019;9:329-41.

51. Hu ZQ, Ma R, Zhang CM, Li J, Li L, Hu ZT, et al. Expression and clinical significance of tyrosine phosphatase SHP2 in thyroid carcinoma. Oncol Lett. 2015;10:1507-12.

52. Cabanillas ME, Ferrarotto R, Garden AS, Ahmed S, Busaidy NL, Dadu R, et al. Neoadjuvant BRAF- and immune-directed therapy for anaplastic thyroid carcinoma. Thyroid. 2018;28:945-51.

53. Iyer PC, Dadu R, Gule-Monroe M, Busaidy NL, Ferrarotto R, Habra MA, et al. Salvage pembrolizumab added to kinase inhibitor therapy for the treatment of anaplastic thyroid carcinoma. J Immunother Cancer. 2018;6:68.

\section{Publisher's Note}

Springer Nature remains neutral with regard to jurisdictional claims in published maps and institutional affiliations.

Ready to submit your research? Choose BMC and benefit from:

- fast, convenient online submission

- thorough peer review by experienced researchers in your field

- rapid publication on acceptance

- support for research data, including large and complex data types

- gold Open Access which fosters wider collaboration and increased citations

- maximum visibility for your research: over $100 \mathrm{M}$ website views per year

At $\mathrm{BMC}$, research is always in progress.

Learn more biomedcentral.com/submissions 